S. K. Son, M. Takeda, T. Endo

Department of Materials Engineering, Yokohama National University, Yokohama, Japan

\title{
Microstructures and thermal stability of metastable-phase precipitates formed in an $\mathrm{Al}-\mathrm{Cu}$ alloy at $463 \mathrm{~K}$
}

The precipitation behavior in an $\mathrm{Al}-\mathrm{Cu}$ alloy isothermally annealed at $463 \mathrm{~K}$ was studied using Vickers microhardness tests, differential scanning calorimetry (DSC) and transmission electron microscopy (TEM). An additional endothermic peak found in the DSC measurements may be attributed to the $\theta^{\prime \prime}$-phase, independent of the dissolution of the G.P. (II) and the $\theta^{\prime \prime}$-phase at the aging temperatures. High-resolution transmission electron microscopy (HRTEM) revealed that the G.P. (I) is formed at a very early stage of isothermal aging, even at $463 \mathrm{~K}$. Comparing the Vickers microhardness and TEM images, it was concluded that the stage at which the G.P. (II) and $\theta^{\prime \prime}$-phases precipitated simultaneously is mainly responsible for the peak hardness.

Keywords: $\mathrm{Al}-\mathrm{Cu}$ alloy; DSC; TEM; HV; Precipitation behavior

\section{Introduction}

$\mathrm{Al}-\mathrm{Cu}$ is an aluminum base alloy that finds many applications as a high-strength, light-weight material. Since the metastable-phase precipitates render the major part of strength, the precipitation sequence in this alloy has been extensively investigated both from the theoretical and the practical point of view for a long period of time. A number of studies clarified the precipitation behavior in the $\mathrm{Al}-\mathrm{Cu}$ alloy, and the precipitation is conventionally recognized to take place in the following sequence: supersaturated solid solution (ssss) $\rightarrow$ G.P. (I) $\rightarrow$ G.P. (II) (or $\left.\theta^{\prime \prime}\right) \rightarrow \theta^{\prime \prime} \rightarrow$ stable $\theta^{\prime \prime}[1-4]$. However, the details of the sequence are not yet completely clarified and some items remain ambiguous [3-15]. For example, (1) how the metastable phases take over the structure and composition of the phase which previously formed in the sequence from the solute cluster G. P. (I) to the stable $\theta$ phase, (2) whether the G. P. (I) appears during high-temperature aging, and (3) how the individual metastable phases and the distribution of particles contribute to the real strengthening of the alloy (although some mechanisms based on the ideas of "cutting-through particle" and "dislocation-loop" were proposed). Previous work conducted at the laboratory of the present authors confirmed the discontinuity of G.P. (I) and G.P. (II) (or $\left.\theta^{\prime \prime}\right)$ [13], but further work is needed to investigate the precipitation sequence and to describe the mechanism of precipitation hardening in a quantitative manner with re- spect to the influence of the shape, size, and distribution of the metastable/stable phases that may contribute to precipitation strengthening.

The present work is aimed to investigate the relationship between the hardness and precipitation sequence of $\mathrm{Al}-$ $\mathrm{Cu}$ alloy at $463 \mathrm{~K}$ by means of differential scanning calorimetry (DSC), transmission electron microscopy (TEM), and Vickers hardness tests.

\section{Experimental procedure}

The compositions of the $\mathrm{Al}-\mathrm{Cu}$ alloy specimens used in this work are listed in Table 1. All specimens were solution-treated at $823 \mathrm{~K}\left(550^{\circ} \mathrm{C}\right)$ for $3600 \mathrm{~s}$ and subsequently quenched in ice water. Artificial aging was subsequently done at $463 \mathrm{~K}$ in an oil bath for various periods between 0 and $6.0 \times 10^{5} \mathrm{~s}$. The Vickers microhardness tests were conducted using a Shimadzu HMV-2000 tester at a load of 0.98 N. A Rigaku TAS300-8230D instrument was used for the DSC measurements with a heating rate of $1.67 \times 10^{-1} \mathrm{~K} / \mathrm{s}$. Bright-field and high-resolution TEM observations were carried out using a Hitachi H-800 microscope at $175 \mathrm{kV}$ and a Topcon EM-002B microscope at $180 \mathrm{kV}$ accelerating voltage, respectively. In all cases, the electron micrographs were taken along the crystallographic $<001>$ orientation in the Al matrices. The details of the experimental procedure used are identical to the previous work conducted by this team, with the exception of the annealing temperature [13].

Table 1. Alloy composition of the $\mathrm{Al}-\mathrm{Cu}$ specimens (at.\%).

\begin{tabular}{|c|c|c|c|c|c|}
\hline & $\mathrm{C}$ & $\mathrm{E}$ & $\mathrm{G}$ & $\mathrm{H}$ & $\mathrm{J}$ \\
\hline $\mathrm{Cu}$ & 0.56 & 1.18 & 1.66 & 1.94 & 2.18 \\
$\mathrm{Al}$ & Bal. & Bal. & Bal. & Bal. & Bal. \\
\hline
\end{tabular}

\section{Results and discussion}

\subsection{Vickers microhardness tests}

Figure 1 shows the Vickers microhardness of specimens aged at $463 \mathrm{~K}$. The hardness curves $\mathrm{C}, \mathrm{E}, \mathrm{G}, \mathrm{H}$, and J are arranged from bottom to top, corresponding to the copper concentration. The hardness of specimen $\mathrm{C}$ and $\mathrm{E}$ is lower than that in the "as-quenched" state during the early stage 
S. K. Son et al.: Microstructures and thermal stability of metastable-phase precipitates formed in an $\mathrm{Al}-\mathrm{Cu}$ alloy

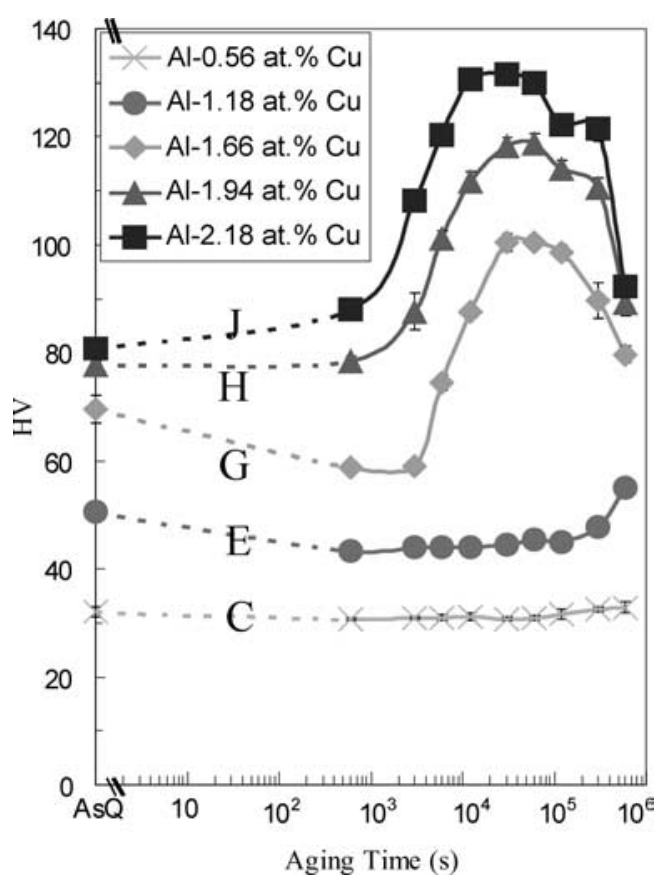

Fig. 1. Vickers hardness of $\mathrm{Al}-\mathrm{Cu}$ specimens in isothermal aging at $463 \mathrm{~K}$.

of annealing. The $\mathrm{HV}$ curves $\mathrm{C}$ and $\mathrm{E}$ rise slightly, even in the later stages of annealing at $3.0 \times 10^{5} \mathrm{~s}$. On the other hand, the hardness values of the $\mathrm{H}$ and $\mathrm{J}$ specimens annealed for $6 \times 10^{2}$ s are not lower than the "as-quenched" state. The Vickers hardness curves rapidly increase after $3.0 \times 10^{3}$ s for specimens $\mathrm{H}$ and $\mathrm{J}$ with high copper concentrations. The hardness of specimen $\mathrm{G}$, with an intermediate concentration, initially decreases after a short period of annealing but then increases after aging for $3 \times 10^{3} \mathrm{~s}$. Thus, the HV curve for specimen $\mathrm{G}$ shows a similar trend to specimens with low copper concentrations during the initial stage of the aging but a trend similar to specimens with high copper concentrations during the later stage of aging. At the final stage of aging, the Vickers hardness curves for specimens $\mathrm{G}, \mathrm{H}$, and $\mathbf{J}$ decrease first gradually as a result of over-aging, and then rapidly. The small shoulder seen after the peak position in the HV curves of the specimens with high copper concentrations may suggest that the primary and secondary peaks of the hardness curves reflect the contribution of two types of precipitates.

Figure 2 shows the relationship between the solute concentration and the Vickers hardness. In the previous work, precipitation hardening occurred for $\mathrm{Al}-\mathrm{Cu}$ specimens containing more than 1.2 at.\% $\mathrm{Cu}$ [13]. The work also confirmed the fact that the hardness curves had three regimes at $433 \mathrm{~K}$. Namely, the hardness had little dependence on the annealing time in the first regime from 0.56 at. $\% \mathrm{Cu}$ to 1.18 at. $\% \mathrm{Cu}$. In the second regime from 1.18 at. $\% \mathrm{Cu}$ to 1.94 at.\% $\mathrm{Cu}$ the hardness increased proportional to the $\mathrm{Cu}$ concentration and annealing time. In the third regime up to 2.18 at. $\% \mathrm{Cu}$, the increment of the HV curve was significantly lower than the second regime. From the present results, we conclude that precipitation hardening of $\mathrm{Al}-\mathrm{Cu}$ occurs at $463 \mathrm{~K}$ for more than 1.2 at.\% Cu, similar as in our previous work at $433 \mathrm{~K}$ [13]. The third regime is, however, observed scarcely in the aging at $463 \mathrm{~K}$, as shown in Fig. 2.

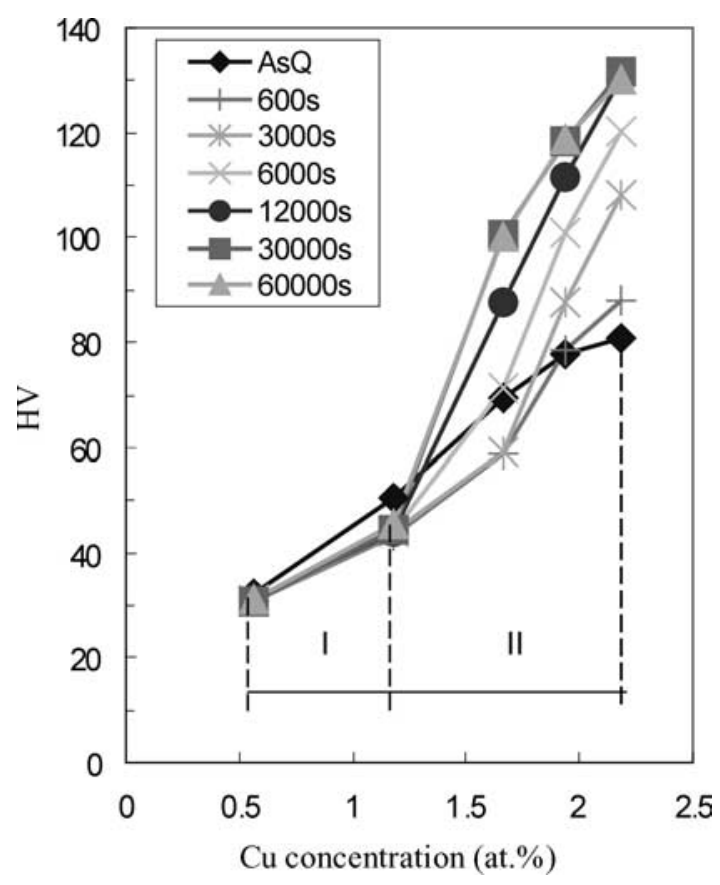

Fig. 2. Composition dependence of Vickers hardness in an $\mathrm{Al}-\mathrm{Cu}$ alloy.

\subsection{Bright-field and high-resolution TEM observations}

Figure 3 shows a series of bright-field TEM images of the microstructures of specimens Al-1.18 at.\% $\mathrm{Cu}(\mathrm{E})$, 1.66 at. $\% \mathrm{Cu}(\mathrm{G}), 1.94$ at. $\% \mathrm{Cu}(\mathrm{H})$ and 2.18 at.\% $\mathrm{Cu}(\mathrm{J})$ aged at $463 \mathrm{~K}$ for $6 \times 10^{2} \mathrm{~s}, 6 \times 10^{3} \mathrm{~s}, 6 \times 10^{4} \mathrm{~s}$, and $6 \times 10^{5} \mathrm{~s}$, respectively. Only few precipitates are formed in specimen $\mathrm{E}$ until $6 \times 10^{5} \mathrm{~s}$ and the microstructure shows that the precipitate contributes little to the hardness. This result is possibly reflected in the fact that the Vickers hardness value increased in the final stage of annealing, as shown in Fig. 1. Fine precipitates can be seen in specimen $G$ aged for longer than $6 \times 10^{3} \mathrm{~s}$, but fine precipitates appear at earlier stages in specimens $\mathrm{H}$ and $\mathrm{J}$ than in specimen $\mathrm{G}$. The increase in $\mathrm{HV}$ hardness from the as-quenched state to that after short annealing (Fig. 1) is probably due to the microstructure. After further aging, the hardness seems to increase proportionally due to the distribution and size of precipitates. At the final stage of aging, the Vickers hardness decreases as a result of over-aging and coarsening of precipitates.

Figure 4a shows a HRTEM image of specimen $\mathrm{H}$ aged at $463 \mathrm{~K}$ for $600 \mathrm{~s}$ together with a simulated image. A typical single-layer platelet corresponding to a $\mathrm{Cu}$-rich plane was mainly observed. This single-layer structure was identified as G. P. (I) in previous papers [8-15]. Mono-, bi-, and multi-layer precipitates are formed in specimen $\mathrm{H}$ aged at $463 \mathrm{~K}$ for $6000 \mathrm{~s}$. Most of the precipitates, however, possess a bi-layer structure like G.P. (II), as shown in Fig. 4 b. Multi-layered precipitates were mainly found in the specimen aged for $6 \times 10^{4} \mathrm{~s}$ (Fig. $4 \mathrm{c}$ ). After aging at $463 \mathrm{~K}$ for $6 \times 10^{5} \mathrm{~s}$ (Fig. 4d), most of the precipitates previously formed disappeared and large precipitates with thick planar-layers corresponding to $\theta^{\prime}$-phase were seen in the Al-1.94 at.\% Cu alloy. 
S. K. Son et al.: Microstructures and thermal stability of metastable-phase precipitates formed in an $\mathrm{Al}-\mathrm{Cu}$ alloy
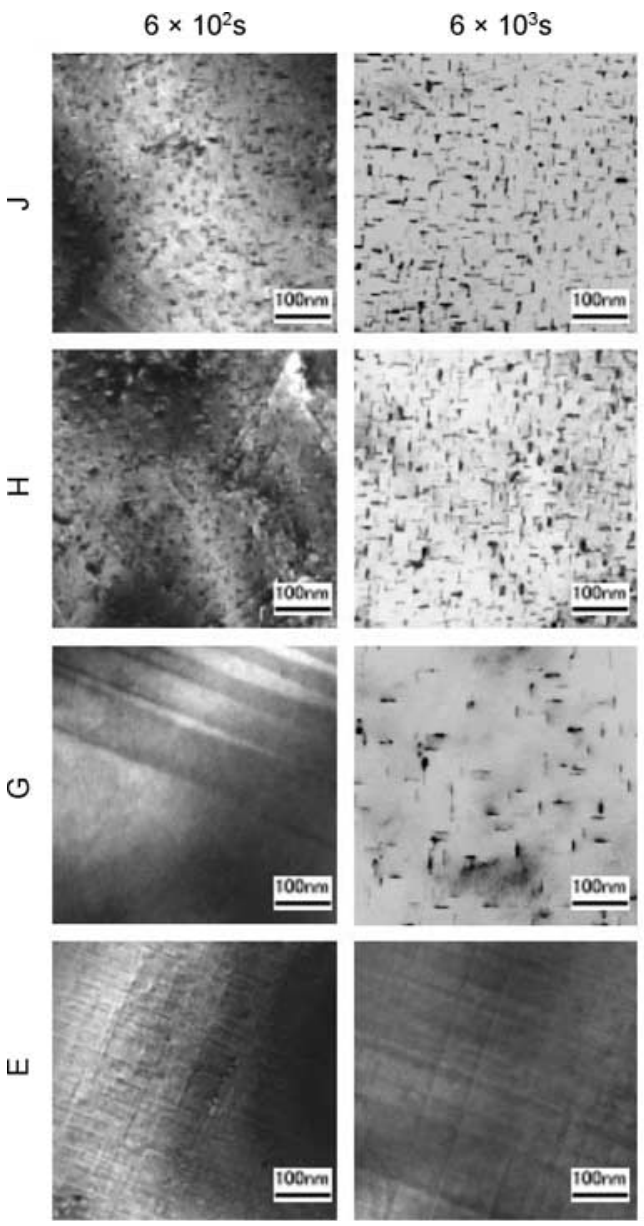
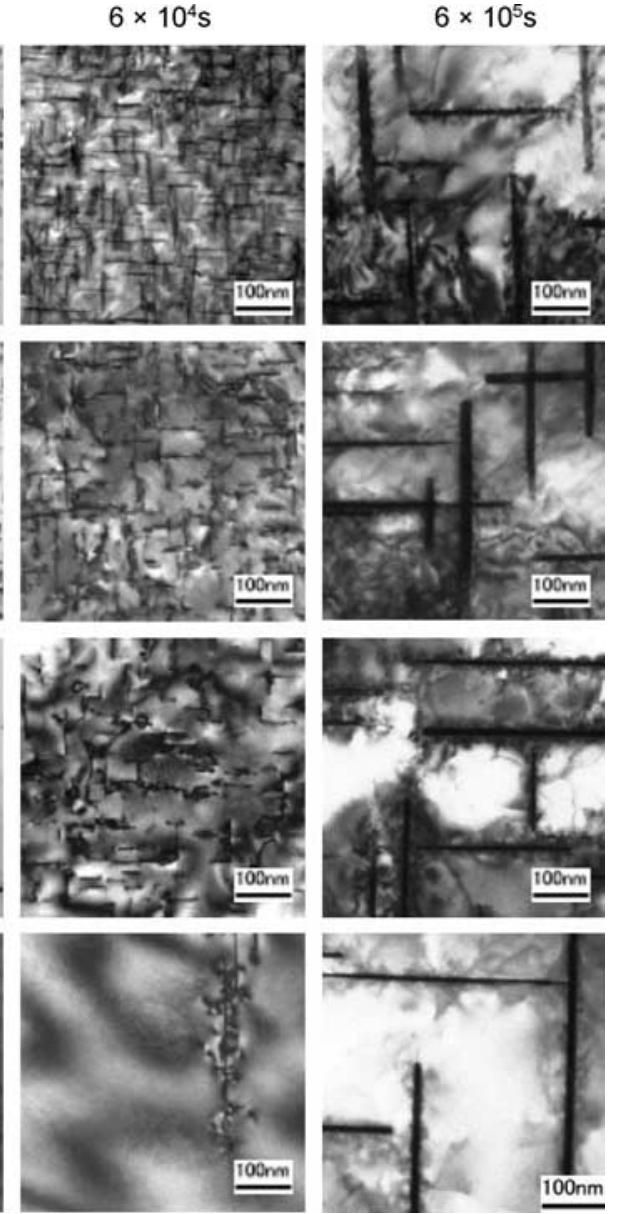

Fig. 3. Bright-field TEM images of Al-1.18 (E), $1.66(\mathrm{G}), 1.94(\mathrm{H})$ and 2.18 at.\% $\mathrm{Cu}(\mathrm{J})$ alloys isothermally aged at $463 \mathrm{~K}$.
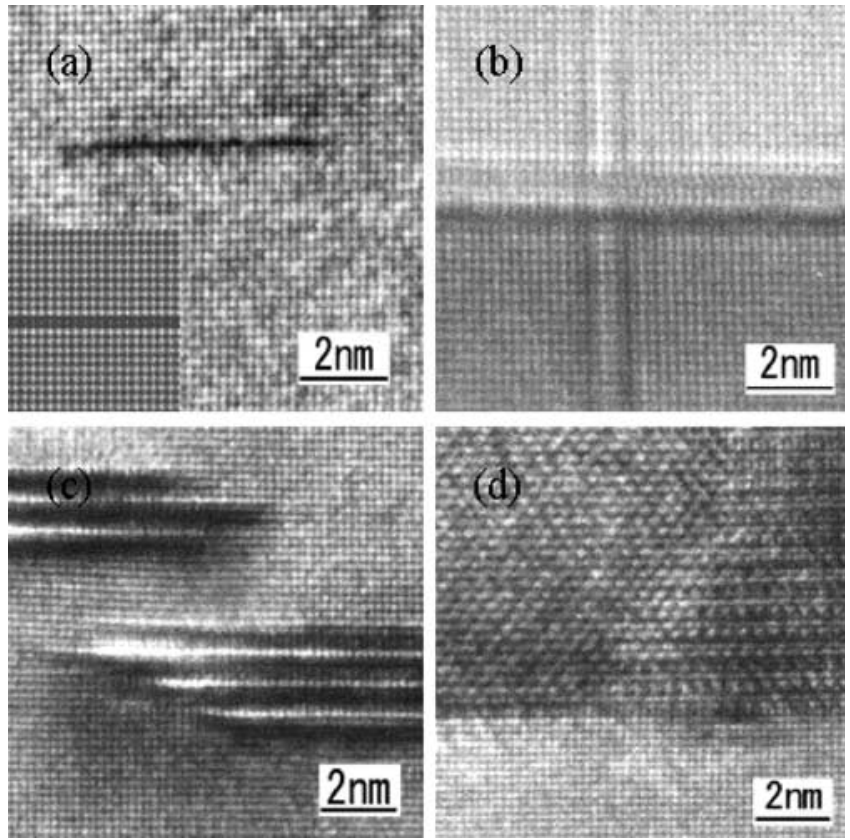

Fig. 4. HRTEM images of $\mathrm{Al}-1.94$ at. $\% \mathrm{Cu}$ aged at $463 \mathrm{~K}$ for (a) $600 \mathrm{~s}$, (b) $6000 \mathrm{~s}$, (c) $60000 \mathrm{~s}$ and (d) $600000 \mathrm{~s}$.

\subsection{DSC measurements}

Systematic DSC measurements provide information on the thermal stability of the stable/metastable phases appearing in the $\mathrm{Al}-\mathrm{Cu}$ alloy. DSC data for the as-quenched and aged $\mathrm{Al}-\mathrm{Cu}$ specimens were shown in our previous work [13] and in several other studies [16-18].

Figure 5a shows DSC curves at various aging times for specimen $\mathrm{H}$ isothermally aged at $463 \mathrm{~K}$, and Fig. $5 \mathrm{~b}$ is an enlarged view of Part A in Fig. 5a. The DSC curves of the alloy $H$ have five endothermic peaks, which appear at around $496 \mathrm{~K}$ (peak e), $516 \mathrm{~K}$ (peak f1), $530 \mathrm{~K}$ (peak f2), $690 \mathrm{~K}$ (peak g), and $773 \mathrm{~K}$ (peak h), respectively. We attribute the first endothermic peak e to the G.P. (I) phase, the second peak f1 to the G.P. (II) phase, the forth peak $g$ to the $\theta^{\prime}$-phase and the fifth peak $h$ to the stable $\theta$-phase in the HRTEM images for specimen $\mathrm{H}$ in the present work and in several previous investigations $[13,16-18]$. The third peak $\mathrm{f} 2$ is, however, not identified by the conventional interpretation established in previous research. The reason that the precipitate at peak $\mathrm{f} 2$ was not explicitly recognized is probably due to the fact that two precipitates causing peaks $\mathrm{f} 1$ and $\mathrm{f} 2$ are simultaneously observed in X-ray diffraction experiments and TEM observations at the peak condition. Unlike previous interpretations, we denoted the new third peak $\mathrm{f} 2$ the " $\theta$ " -phase". Thus, the precipitation sequence in the $\mathrm{Al}-\mathrm{Cu}$ alloy aged at $463 \mathrm{~K}$ is proposed as: supersaturated solid solution $\rightarrow$ G.P. (I) $\rightarrow$ G.P. (II) $\rightarrow$ $\theta^{\prime \prime} \rightarrow \theta^{\prime} \rightarrow \theta$.

Comparing the present DSC results with the hardness curves shown in Fig. 1, we confirmed that the peak hardness plateau appeared in the transition period when the G.P. (II) was transformed into the $\theta^{\prime \prime}$-phase in specimens $\mathrm{H}$ and J. Furthermore, the higher the density of the fineplatelet phases homogeneously precipitated in the matrix at high copper concentration, the more the hardness increases. This result differs from most former research, where the G. P. (II) and $\theta^{\prime}$-phases were attributed as the precipitates mainly responsible for peak hardness. As aging proceeded, the hardness values clearly decreased as the $\theta^{\prime \prime}$ phase closely precipitated after annealing for $1.2 \times 10^{5} \mathrm{~s}$. At the final stage of aging, HV decreased drastically by the precipitation of the $\theta^{\prime}$-phase.

Based on the present results of the Vickers microhardness, DSC measurements, and TEM observations, the relationship between the peak hardness and the metastablephase dependence on annealing time for the C, E, G, H, and $\mathrm{J}$ alloys aged at $463 \mathrm{~K}$ is illustrated in Fig. 6. In Fig. 6, 
S. K. Son et al.: Microstructures and thermal stability of metastable-phase precipitates formed in an $\mathrm{Al}-\mathrm{Cu}$ alloy
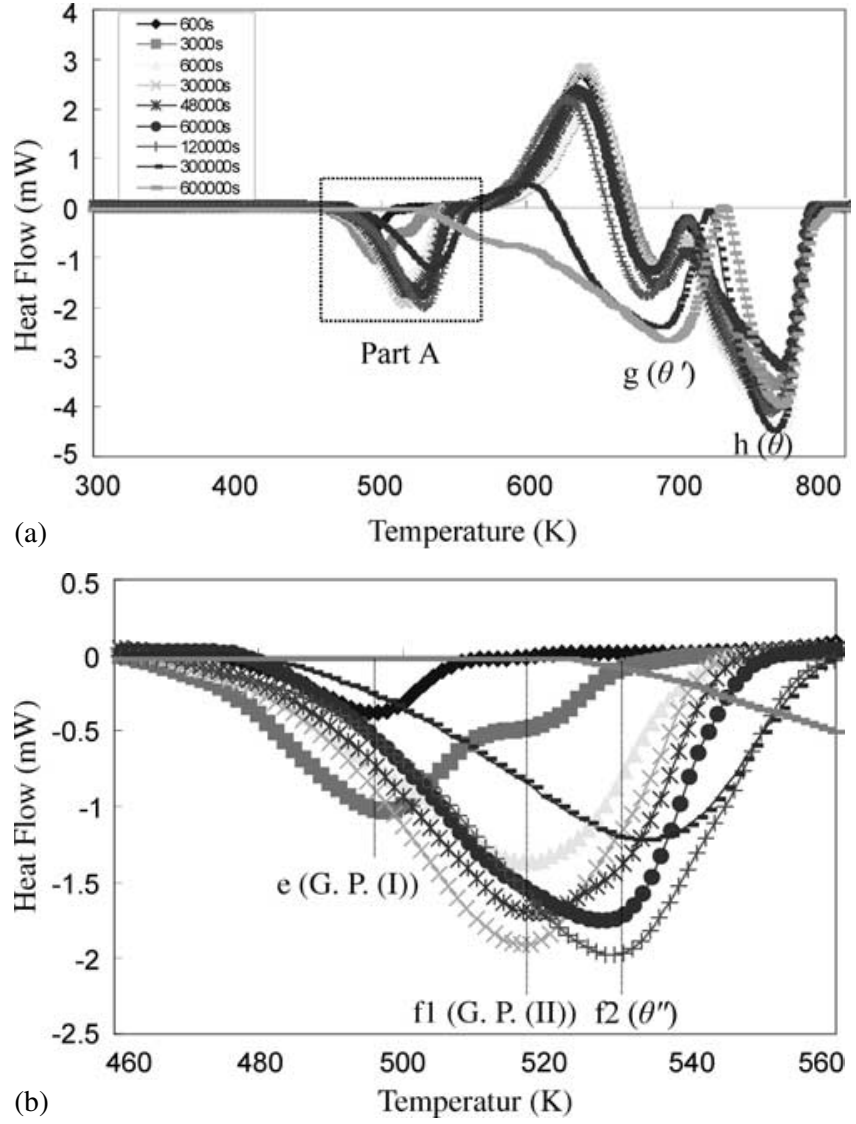

Fig. 5. DSC curves for an Al-1.94 at.\% Cu specimen aged at $463 \mathrm{~K}$.

the metastable phase observed at each aging condition is shown and we see that the peak hardness is associated with the G.P. (II) and $\theta^{\prime \prime}$-phase. Three overlapping metastable phases are found simultaneously at some aging conditions, which seems to suggest that the transition speed is rapid due to the large heat flow supplied during isothermal aging at $463 \mathrm{~K}$. Although the overlap durations may bring an argument on the precipitate mainly responsible for the hardness, we determined that G. P. (I) is mono-layer, G. P. (II) is bi-layer, and $\theta^{\prime \prime}$ is multi-layer with at least three copperlayers using HRTEM and HAADF-STEM [19]. Furthermore, we confirmed that the new interpretation is consistent with the aging process at other temperatures (373-493 K). Details of the investigation on temperature dependence of the aging process will be published in other papers.

\section{Summary}

The present work investigated the sequence of precipitation in an $\mathrm{Al}-\mathrm{Cu}$ alloy at $463 \mathrm{~K}$ using Vickers microhardness tests, TEM observations, and DSC measurements. The following conclusions were attained from the results of the present work.

1. High-resolution transmission electron microscopy (HRTEM) revealed that the G. P.(I) is formed at a very early stage of isothermal aging at $463 \mathrm{~K}$.

2. An additional endothermic peak was found in DSC measurements that may be attributed to the $\theta^{\prime \prime}$-phase, independent of the formations of the G.P. (II) and the $\theta^{\prime}$-phase at aging temperatures.

3. Based on the results of DSC measurements and observation of TEM micrographs, the precipitation sequence

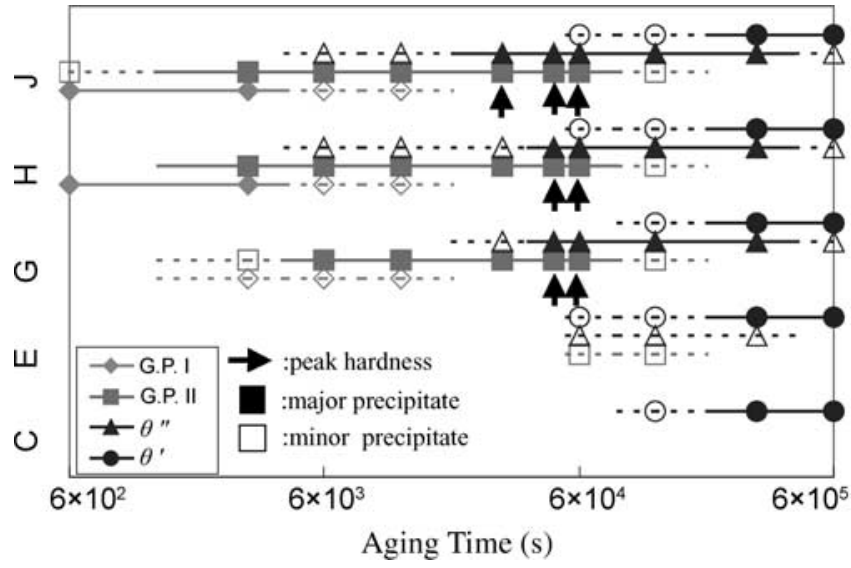

Fig. 6. Relationship between the peak hardness and the dependence of metastable phase on annealing time for the C, E, G, H, and J alloys aged at $463 \mathrm{~K}$.

$\uparrow$ : peak hardness, $\square$ : major precipitate, $\square$ : minor precipitate

in an $\mathrm{Al}-\mathrm{Cu}$ alloy at $463 \mathrm{~K}$ is confirmed as follows: supersaturated solid solution $\rightarrow$ G.P. (I) $\rightarrow$ G.P. (II) $\theta^{\prime \prime} \rightarrow \theta^{\prime} \rightarrow \theta$.

4. Comparing the Vickers microhardness and TEM images, it is concluded that the simultaneous precipitation of the G. P. (II) and $\theta^{\prime \prime}$-phases is mainly responsible for the peak hardness.

\section{References}

[1] A. Guinier: Ann. Phys. 12 (1939) 161

[2] G.D. Preston: Phil. Mag. 26 (1938) 855.

[3] J.M. Silcock, T.J. Heal, H.K. Hardy: J. Inst. Metals. 82 (1953-4) 239.

[4] V. Gerold: Z. Metallkd. 45 (1954) 593.

[5] D.R. James, G.L. Liedl: Acta Cryst. 18 (1965) 678.

[6] X. Auvray, P. Georgopoulos, J.B. Cohen: Acta Metal. 29 (1981) 1061.

[7] E. Bubeck, V. Gerold: J. appl. Crystal. 19 (1986) 164.

[8] V. Gerold: Scripta metall. 22 (1988) 927.

[9] B. Jouffrey, M. Karlik: Microsc. Microanal. Microstruct. 3 (1992) 243.

[10] H. Fujita, C. Lu: Mater. Trans. JIM. 33 (1992) 892.

[11] S. Czezor, L. Lochte, G. Gottstein, P. Staron, R. Kampmann: Phys. Stat. Sol. (a) 182 (2000) 631

[12] M. Karlik, A. Bigot, B. Jouffrey, P. Auger, S. Belliot: Ultramicroscopy 98 (2004) 219

[13] M. Takeda, Y. Maeda, A. Yoshida, K. Yabuta, S. Konuma, T. Endo: Script. Mater. 41 (1999) 643.

[14] V.A. Philips: Acta Metal. 21 (1973) 219

[15] T. Sato, A. Kamio: Mater. Sci. Eng. A 146 (1991) 161.

[16] J.M. Papazian: Metall. Trans. A 12 (1981) 269.

[17] C.G. Cordovilla, E. Louis: J. Mat. Sci. 19 (1984) 279.

[18] M.J. Starink, P. van Mourik: Mat. Sci. Eng. A 156 (1992) 183.

[19] S.K. Son, M. Takeda, M. Mitome, Y. Bando, T. Endo: Materials Letters 59 (2005) 629.

(Received July 28, 2004; accepted December 17, 2004)

Correspondence address

Sung-Kyu Son

Department of Materials Engineering (SEISAN)

Yokohama National University

c/o Dr. Takeda, Department of Materials Engineering (SEISAN)

Faculty of Engineering, Yokohama National University

79-5 Tokiwadai, Hodogaya-ku, Yokohama, 240-8501 Japan

Tel: +81453393855

Fax: +81453393855

E-mail: d02sa391@ynu.ac.jp 